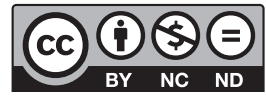

Estudos Teológicos foi licenciado com uma Licença Creative Commons Atribuição - NãoComercial - SemDerivados 3.0 Não Adaptada

http://dx.doi.org/10.22351/et.v59i1.3410

\title{
Oralidade no Evangelho de Marcos ${ }^{1}$
}

\author{
Orality in the Gospel of Mark
}

\section{Sidney de Moraes Sanches ${ }^{2}$}

Resumo: Este artigo tem por assunto a oralidade no Evangelho de Marcos. Seu objetivo primário é apontar para o substrato oral do texto escrito marcano, e o secundário é propor modos de observação das marcas da oralidade nele. Para isso me valho dos estudos sobre a tradição oral de Jan Vansina; sobre a oralidade de Werner Kelber e James Dunn; sobre a transmissão oral de Kenneth Bailey. Acrescento a contribuição da análise da narrativa (narrative analysis), focalizando o plano narrativo como meio complementar para o exame do relato oral. Apresento, como exemplo, o episódio de cura da mulher com hemorragias. Concluo, com James Dunn, que é possível reconhecer os vestígios de oralidade no texto marcano. E que esses servem para preencher o espaço entre Jesus e as primeiras transcrições e edições da tradição oral, cujo primeiro exemplar está no Evangelho de Marcos.

Palavras-chave: Evangelho de Marcos. Oralidade. Tradição oral. Jesus histórico. Plano narrativo.

\begin{abstract}
This article deals with orality in the Gospel of Mark. Its primary objective is to point to the oral substrate of the written text of Mark, and the secondary one is to propose ways of observing the marks of orality in it. For this I have used studies about oral tradition of Jan Vansina; about orality of Werner Kelber and James Dunn; about oral transmission of Kenneth Bailey. I have added the contribution of narrative analysis, focusing on the narrative plot as a complementary means for the exam of the oral report. I present, as example, the episode of healing of the woman with bleeding. I conclude, with James Dunn, that is possible to recognize the traces of orality in the Mark's text. And this serves to fill the gap between Jesus and the first transcriptions and editions of the oral tradition, whose first exemplar we have in the Gospel of Mark.
\end{abstract}

Keywords: Gospel of Mark. Orality. Oral tradition. Historical Jesus. Narrative Plot.

1 O artigo foi recebido em 03 de agosto de 2018 e aprovado em 23 de fevereiro de 2019 com base nas avaliações dos pareceristas ad hoc.

2 Doutor em Teologia pela Faculdade Jesuíta de Filosofia e Teologia (FAJE), onde também fez pós-doutorado de 2017-2018 com bolsa PNPD/CAPES, em Belo Horizonte, Minas Gerais. Contato: sidneysanches5556@ gmail.com 


\section{Introdução}

O Evangelho de Marcos representa um movimento intenso de relatos orais do primeiro século pelo qual se diziam e se ouviam notícias sobre Jesus de Nazaré. O texto marcano é uma transcrição e edição de muitos desses relatos. Esses devem ser examinados em sua dinâmica vivencial, informal e não controlada, do modo como foram enunciados oralmente antes da composição do texto escrito. Começo pela análise antropológica da transmissão da tradição oral desenvolvida por Jan Vansina. Depois exponho as teorias que dois pesquisadores da oralidade no texto de Marcos. Werner Kelber investiga a herança oral do evangelho marcano. James Dunn examina o Evangelho de Marcos no conjunto da tradição sinótica, observando a dinâmica verbal dos testemunhos. Minha iniciativa consiste em ampliar a análise dos relatos orais recorrendo à contribuição da análise da narrativa (narrative analysis) com foco no plano narrativo (narrative plot) e na perspectividade (focus) do narrador e dos personagens. Por fim, ofereço um exemplo de observação e análise do episódio de cura da mulher com hemorragia, de modo a demonstrar a razoabilidade das teorias apresentadas.

\section{Jan Vansina e a tradição oral}

Falando sobre a tradição oral, James Dunn entende que:

a tradição do evento não é propriamente o evento mesmo. E a tradição do dito não é o próprio dito. A tradição é, na melhor das hipóteses, a testemunha do evento, e como presumivelmente estavam presentes várias testemunhas, pode muito bem ter havido várias tradições ou versões da tradição desde o começo ${ }^{3}$.

Sendo assim, é importante considerar o processo ou cadeia de transmissão oral no ambiente das congregações cristãs no espaço localizado entre Jesus e o primeiro evangelho. Para isso, recorre-se ao trabalho de Jan Vansina, que se ocupou da observação da cadeia de transmissão de tradições orais entre tribos na África central. Seus resultados são importantes para entender de que modo as congregações cristãs, também imersas em uma sociedade tradicionalmente oral, cultivaram cadeias de transmissão de tradições orais acerca de Jesus de Nazaré.

Vansina demonstrou que a tradição oral é cultivada em comunidades cujo ambiente de comunicação é predominantemente, senão exclusivamente, oral. Desse ponto de vista, a tradição oral é uma fonte histórica como outra qualquer, sendo sua característica definidora a transmissão verbal que se dá em uma cadeia de testemunhos ou relatos orais. Duas exigências são determinantes para definir esse relato: ele é verbal, portanto não escrito; ele é narrado, pois diz respeito ao passado.

3 DUNN, James D. G. Jesus em Nova Perspectiva. O que os estudos sobre o Jesus histórico deixaram para trás. São Paulo: Paulus, 2013. p. 66. (itálicos do autor). 
Começando no fato particular observado em um relato inicial, continua-se por uma cadeia de transmissão verbal até o relato final, quando se dá o primeiro registro escrito. O relato ou testemunho ocular é um tipo de relato oral, somente acessível quando recolhido em uma tradição oral. Portanto um relato ou testemunho verbal é “[...] o conjunto de declarações feitas por uma mesma testemunha concernente a uma mesma série de acontecimentos, na medida em que tenham uma mesma referência""4. Assim, o relato é limitado e até condicionado pela personalidade e interesses da testemunha e pelo seu modo de testemunhar. Também é delimitado pelo fato, pelo modo como foi inicialmente comunicado e pela cadeia de transmissão.

Há dois tipos de relatos orais. Aquele que é aprendido de memória e transmitido do modo como foi recebido a partir de uma regra determinada. Aquele que é livre e é transmitido ao gosto de cada testemunha, sem os condicionamentos da memória e de uma regra fixa. Disso resulta que o relato é individual uma vez que a testemunha, sozinha, dá conta de uma tradição oral conhecida. E também é coletivo, sendo conservado por um grupo de pessoas que nomeia uma, ou mais de uma delas, para transmitir o testemunho sob rigoroso controle da coletividade. Nesse último caso, são desenvolvidas técnicas e normas para a transmissão do testemunho de modo a conservá-lo fielmente, quanto ao modo e conteúdo, comunicado de uma geração para outra. A correção da transmissão pode ser garantida por algum grau de redução a um grupo pequeno, ou pela associação com recursos mnemotécnicos, como: objetos, cores, números, lugares, animais, outros fatos, canto, dança, ações, rituais etc.

Do testemunho inicial até o final pode haver alteração ocasionada pela perda da memória e a adição de explicações. A própria tradição oral se encarregou de lidar com essas situações fortalecendo a capacidade de atenção e retenção do testemunho, criando mecanismos de controle e reduzindo o tempo entre uma transmissão e outra.

O relato oral pode ser consciente e voluntário, ou inconsciente e involuntário. Seu objetivo nem sempre é histórico tal como definido modernamente. Seu papel é, principalmente, social e seu objetivo é dado conforme a função ocupada no interior da tradição oral da qual participa. Ele não possui um gênero discursivo próprio e constante, sendo que tanto o modo de transmissão como a forma de atestá-la dependerão do quanto o testemunho é controlado ou livre. Essa depende da funcionalidade ou papel do testemunho na cultura de transmissão da tradição: poesia, canto, encenação etc. Existem textos mais fixados na tradição oral e outros com critérios mais livres e sujeitos às variações de testemunhas individuais. A única característica discursiva comum ao relato oral é o seu conteúdo narrativo.

O sentido ou interpretação do relato oral é o objeto de estudo de um documento escrito que retém a tradição oral. A interpretação considera, em primeiro lugar, as categorias linguísticas no qual o relato foi transmitido. Em segundo lugar, os elementos de expressão oral individuais e coletivos da tradição oral. E, em terceiro lugar, a representação ou reverberação da realidade no modo como foi transmitida, desde a testemunha inicial até a última, visto que nesse procedimento se "[...] deforma a realidade

4 VANSINA, J. La Tradición Oral. Barcelona: Labor, 1966. p. 36. 
voluntária ou involuntariamente, já que não recebe mais que uma parte dela e atribui um significado que lhe aprecia"s. Cabe ao intérprete do relato oral situá-lo junto com os fatores: sociedade, cultura e individualidade que podem tê-lo modificado.

Assim sendo, Vansina propõe três momentos na análise do relato oral. O primeiro diz respeito ao quanto realmente foi observado e significado pela testemunha ocular, e o que foi preservado e alterado na cadeia de transmissão até a última testemunha. $\mathrm{O}$ segundo tem a ver com um ou mais testemunhos paralelos com os quais se pode fazer um exame comparativo. O terceiro é a comparação entre as circunstâncias geradoras dos diversos testemunhos a fim de estabelecer conexões entre eles que ampliem sua base de investigação.

Ora, dissemos que os resultados da investigação de Vansina são úteis para nossa compreensão do processo de transmissão oral ocorrido entre as congregações cristãs no período entre a morte de Jesus de Nazaré e a redação do Evangelho de Marcos. Primeiro, há a valorização da tradição oral como fonte histórica para o conhecimento do modo de vida e de fé das primeiras congregações seguidoras do Nazareno. Segundo, sabemos acerca dos meios e modos de acolhimento, transmissão e preservação de uma tradição oral no ambiente dessas congregações nazarenas. E, terceiro, recebemos um modo de acessar e interpretar o relato oral presente no texto evangélico, algo muito próximo do que já temos como método histórico-literário de análise da tradição e da redação. Todavia, não com ênfase no material escrito, e sim no material oral de cuja memória aquele é testemunha.

\section{Werner Kelber e a herança oral do Evangelho de Marcos}

Kelber sugeriu que o substrato do Evangelho de Marcos está na linguagem oral e, por consequência, é possível encontrar os traços e vestígios de uma herança oral dentro do seu texto escrito. Ele reconhece as limitações em buscar pela linguagem oral a partir de um texto escrito, visto que

palavras proferidas não são acessíveis no meio escrito. Os acontecimentos se tornam narrativas de acontecimentos. [...] palavras que foram vivas são reduzidas ao silêncio; os contextos onde elas foram pronunciadas são irremediavelmente perdidos. Isto pode significar, então, que as formas orais podem ter sido textualizadas a ponto de se tornarem irreconhecíveis ${ }^{6}$.

Essa aparente impossibilidade, entretanto, tem outra face. Se no longo prazo a escrita pode apagar os traços da linguagem oral, no curto prazo ela pode, ainda, preservá-los em um estado fóssil. Até mais, ela pode reter suas características formais viabilizando a identificação dos traços distintamente orais da linguagem falada. A

VANSINA, 1966, p. 93.

6 KELBER, Werner. Tradition Orale et Écriture. Paris: du Cerf, 1991. p. 75, 76. 
análise que possibilita esse acesso não é literária, na qual se trabalha sobre o texto escrito. Antes, é

no exame das formas orais que descobriremos como a informação se organiza e se ordena a conceituação. As formas do discurso na tradição sinótica revelam uma multidão de necessidades e de funções orais, de processos de pensamento oral ${ }^{7}$.

Apesar do Evangelho de Marcos conter um número grande de parábolas que poderiam ser o lugar natural do fenômeno oral, é nos relatos onde melhor se apresenta a tradição oral possibilitando o reconhecimento de uma linguagem oral pré-marcana. Os quatro grupos de narrativas onde se pode discernir a herança oral remanescente são: de cura ou heroicas, de polarização, didáticas e parabólicas.

Interessa, de perto, os primeiros grupos: de relatos heroicos e de polarização como atos de Jesus de Nazaré. Nos dez relatos de cura ou heroicos (1.29-31; 1.40-45a; 2.1-12; 3.1-6; 5.21-24,35-43; 5.25-34; 7.24-30; 7.31-37; 8.22-26; 10.46-52), Kelber identificou uma organização literária que reflete a estrutura de um relato oral, sendo seus traços típicos: a uniformização da estrutura e a variedade de experiências de cura; o enredo dramático ao redor de duas personagens: o doente e o curador, e de dois elementos: doença e cura; a ênfase no acontecimento sobrenatural em detrimento da ação ordinária; a redução da ação dos personagens a uma única atitude: súplica e cura. Surge uma cristologia oral, "conforme as exigências da retórica oral, da reminiscência oral, da reprodução oral"», onde Jesus é o herói no nível da realidade ordinária, que a transforma por sua ação extraordinária. Em resumo, “a pluralidade, uniformidade e a variedade das narrativas de cura atestam que sua produção e a qualidade de sua execução são orais"'.

Nos três relatos de polarização (1.21-28; 5.1-20; 9.14-29), temos a presença da mesma organização uniforme que permite grande variação na execução narrativa, onde partes são ampliadas e reduzidas e até modificadas, dependendo do público e do improviso necessário. Seus enredos são resultado da atividade oral, os temas de enfrentamento são típicos de uma mentalidade oral. A realidade é dividida entre dois princípios encarnados em dois personagens que se enfrentam, com cores éticas, um mau e outro bom, sendo que o bom vence o mau. A ideia é captar a imaginação do público antes de reconstruir uma experiência histórica. ${ }^{10}$

A organização da execução oral é a seguinte: ${ }^{11}$

\footnotetext{
KELBER, 1991, p. 76.

8 KELBER, 1991, p. 88.

9 KELBER, 1991, p. 86.

${ }^{10}$ KELBER, 1991, p. 89-92.

${ }^{11}$ KELBER, 1991, p. 79, 89.
} 


\begin{tabular}{|l|l|}
\hline Relatos de cura & Relatos de polarização \\
\hline I. Exposição da cura & I. Confrontação \\
a) chegada do curador e da doença & a) encontro do exorcista e do possesso \\
b) cenário do público (espectadores) & b) fórmula preventiva do demônio \\
c) indicação da doença & c) o exorcista o repreende e impõe silêncio \\
d) pedido de socorro & \\
e) desprezo ou ceticismo do público & II. Expulsão \\
$\begin{array}{l}\text { II. Realização da cura } \\
\text { a) anúncio de uma fórmula de cura } \\
\text { b) gestos curadores }\end{array}$ & a) ordem de sair \\
c) afirmação da cura & b) saída violenta do demônio \\
III. Confirmação da cura & III. Aclamação \\
a) fórmula de admiração/confirmação & a) fórmula coral \\
b) reenvio da pessoa curada & b) propagação da notícia \\
c) injunção de guardar o segredo & \\
d) propagação da reputação do curador & \\
\hline
\end{tabular}

* Execução oral por trás da organização literária das narrativas (adaptação minha).

Outro elemento atestador da presença da oralidade é a sintaxe discursiva dos relatos. Eles são reunidos entre os capítulos 1 a 13, comumente curtos, integrando a espinha dorsal do evangelho. Essa consiste em: (a) escolhas lexicais: sentenças iniciadas por kai egeneto ou kai ginetai; ou pelos advérbios euthys e kai euthys ou palin e kai palin; e sentenças paratáxicas com kai; (b) escolhas retóricas: tríades, duplos, uso do passivo, terceira pessoa do plural, presente histórico com legein e erchesthai, discurso direto, passagem do discurso indireto para o direto, acumulação, repetição de palavras, cláusulas, temas; (c) escolhas narrativas: preferência da ação sobre a palavra; descrição dos personagens em ação, de modo que essas dão forma aos personagens.

\section{James Dunn e a oralidade na tradição sinótica}

James Dunn tem sido um dos principais fomentadores sobre a importância de dar atenção à cultura da oralidade no mundo greco-romano, sobretudo naquele sírio-galilaico, no qual se constituíram as primeiras congregações cristãs. Ele critica a imposição hegemônica do paradigma histórico-literário atribuindo-o ao advento da Modernidade ocidental, e a consequente rejeição do paradigma oral-aural que moldava as culturas da Antiguidade. Segundo ele, é preciso maior entendimento sobre o funcionamento das sociedades de oralidade e da transmissão oral das tradições dentro delas, para reconstruir as origens e fontes dos evangelhos e, então, da pessoa de Jesus de Nazaré. Conforme ele, é fato que "não deveríamos esquecer o papel contínuo das testemunhas oculares formadoras de tradição, daqueles que foram reconhecidos, desde o princípio, como apóstolos ou portadores autorizados (tradents) da tradição de 
Jesus"12. No entanto, insiste que, no período entre Jesus e as primeiras transcrições do Evangelho de Marcos, coletividades inteiras e indivíduos transmitiram, constantemente, sua experiência vivida com ele. Esses testemunhos orais reunidos no Evangelho de Marcos construíram uma memória popular, não oficial nem autorizada de Jesus de Nazaré. Conforme ele:

O primeiro é que o ensinamento de Jesus foi dado oralmente; ele começou oralmente. E o segundo é que podemos pressupor com segurança que as notícias sobre Jesus foram inicialmente repassadas oralmente. As narrativas sobre Jesus sem dúvida foram objeto de muitas conversas em bazares e ao redor de fogos de chão. Não há dúvida de que discípulos de Jesus falaram sobre o que acabaram de ver Jesus fazer e sobre seu ensinamento. Isso foi o início da tradição sobre Jesus, foi objeto de celebração e meditação nos grupos de seus seguidores em termos orais, foi repassado oralmente para os curiosos, a quem perguntava e aos novos discípulos. Podemos pressupor com certeza que o período entre Jesus e os evangelhos foi preenchido com essa tradição ${ }^{13}$.

Dunn, então, propõe reavaliar a tradição literária sinótica ou os paralelismos entre os três primeiros evangelhos: Mateus, Marcos e Lucas, não do ponto de vista das semelhanças, mas das diferenças entre eles no tratamento dos mesmos assuntos. Ele adverte que o estudo crítico-formal das fontes dos evangelhos advoga uma interdependência literária entre eles, onde Mateus e Lucas teriam se utilizado dos textos escritos de Marcos e de outra fonte, Quelle. Isso explica quando os três concordam, mas não explica quando os três divergem, mesmo lidando com o mesmo assunto: "Se não damos às diferenças uma atenção tão proeminente quanto a que damos às similaridades, não corremos o risco de não conseguir apreciar o caráter pleno ou real da tradição sobre Jesus e do modo como os evangelistas lidaram com ela?"'14.

Dunn propõe a análise comparativa entre os três evangelhos naqueles casos onde "não há uma estreita correspondência verbal e, em alguns casos, dificilmente há qualquer correspondência verbal, embora o tema seja evidentemente o mesmo" ${ }^{\prime 1}$. Sugere observar a falta de correspondência verbal mesmo quando o assunto é idêntico. E, acrescentamos, a presença de mais detalhes por um evangelista do que em outros, quando a narrativa é a mesma. Isso sugere aquilo que Kelber já apontou anteriormente: a diversidade de expressão, quando existe o mesmo discurso ou narrativa, é evidência da tradição oral. ${ }^{16}$

\footnotetext{
12 DUNN, James D. G. Jesus Remembered. Grand Rapids: Eerdmans, 2003. p. 243.

13 DUNN, 2013, p. 48. (itálicos do autor).

14 DUNN, 2013, p. 50.

15 DUNN, 2013, p. 54. (itálicos e negritos do autor).

16 DUNN, 2013, p. 63-72.
} 


\section{Sobre a transmissão oral no Evangelho de Marcos}

No texto escrito chamado Evangelho de Marcos, temos relatos ou testemunhos orais que privilegiam o gênero narrativo. Eles refletem a atividade de um contador de histórias como: "um performer oral que tinha ouvido a estória lida em voz alta, ou ouviu a estória performada, quem tornava a recontar a estória em interação com um grupo de ouvintes"17.

Bailey $^{18}$, estudioso dos processos de transmissão oral entre sociedades orais do Oriente Médio, sugere que até o levante da guerra judaico-romana, nos anos de 70, as congregações cristãs cultivaram uma transmissão oral, controlada, informal dos testemunhos sobre Jesus de Nazaré. Com a guerra, boa parte das aldeias onde estavam as congregações foi destruída, obrigando seus habitantes, inclusive os cristãos, a se deslocarem. Onde se assentaram, de novo, o processo de transmissão oral foi continuado por seus membros, que ainda retinham na memória os testemunhos originais. E, assim, o processo foi continuado até a transcrição e edição do texto marcano. O processo de transmissão prosseguiu mesmo após sua publicação.

Horsley tem orientado sua pesquisa recente para os processos orais que estão nas origens do Evangelho de Marcos. Segundo ele, o evangelho é literatura popular que conta a história de um líder igualmente popular. Esse defendeu os interesses dos aldeões (villagers) e da gente comum (ordinary people) em oposição às elites cultural e política regionais: os Herodes, na Galileia; e local: as autoridades judaicas e romanas, em Jerusalém. Sua redação não atendia aos padrões da alta cultura greco-romana nem da ideologia historiográfica helenística. ${ }^{19}$

No período em que Marcos transcreveu os testemunhos orais registrados em seu evangelho, e mesmo anteriormente a ele, predominava o baixo nível de letramento e alfabetização da população sírio-galilaica. Os textos eram usados em circunstâncias absolutamente necessárias: a justiça, os negócios, a política, a religião, a correspondência pública e privada. Mesmo no ambiente das escolas escribais e rabínicas, onde a Torá era estudada, predominava a oralidade, mediante a memorização e repetição. Em toda a região e além preponderava a oralidade como meio privilegiado de contato e transmissão de ideias. ${ }^{20}$

Portanto pode-se ver o texto marcano como uma celebração inesquecível de Jesus de Nazaré performada por seus seguidores. Essa era repetida toda vez que ele era lido oralmente, vez após vez, para uma audiência. Horsley pleiteia que:

17 DEWEY, Joanna. The Gospel of Mark as an Oral-Aural Event: Implications for Interpretation. In: MCKNIGT, Edgar V.; MALBON, Elizabeth S. (Eds.). The New Literary Criticism and the New Testament. Pennsylvania: Trinity, 1994. p. 145. Optamos, aqui, pela tradução literal do termo inglês story para designar uma narrativa não historiográfica, de acordo com a distinção: history e story.

18 BAILEY, Kenneth. Informal Controlled Oral Tradition and the Synoptic Gospels. Themelios, v. 20, n. 2 , p. 4-11, 1995. Disponível em: <https://pt.scribd.com/document/353281537/Article-Kenneth-Bailey-OralTradition-Synoptic-Gospels>. Acesso em: 22 jul. 2018.

19 HORSLEY, Richard A. Oral and Written Aspects of the Emergence of the Gospel of Mark as Scripture. Oral Tradition, v. 25, n. 1, p. 100, 2010. Disponível em: <http://journal.oraltradition.org/issues/25i/ horsley>. Acesso em: 11 ago. 2017.

${ }^{20}$ HORSLEY, 2010, p. 98. 
Em suma, o Evangelho de Marcos não foi um bom candidato a se tornar escritura conforme os modelos e padrões prevalecentes nos círculos judaicos escribais ou intelectuais greco-romanos. Como história sobre um líder profético popular de um movimento de renovação entre pessoas comuns na Galileia, ele foi regularmente representado na forma oral entre outras comunidades de povos comuns em um raio cada vez mais amplo. [...] Com forte repercussão entre a população, essas histórias de pessoas comuns foram também eventualmente reconhecidas pela emergente hierarquia da Igreja estabelecida como integrante do cânon do Novo Testamento ${ }^{21}$.

Não somente o Evangelho de Marcos é uma transcrição de relatos orais recolhidos de uma ou mais tradições orais. Ele mesmo é uma performance oral desses relatos, sendo seu plano e estilo mais adequadamente descritos como uma composição ou documento oral. ${ }^{22}$ Essa hipótese foi desenvolvida por Joanna Dewey. Ela compara o ato comunitário tão comum nos dias de hoje de quando o povo cristão se reúne para ouvir, em voz alta, a leitura de uma porção do Evangelho de Marcos, com a experiência bem mais comum de uma antiga congregação cristã reunir-se para ouvir o evangelho ser lido em voz alta. A experiência é tão facilmente comparável que se pode dizer que o texto escrito de Marcos foi composto para favorecer a leitura oral, audível, congregacional. Não apenas o texto favoreceria a audição, mas também a memorização, uma vez que boa parte da leitura era efetivada de memória numa espécie de recitação. Em um período de uma hora e meia a duas horas, "um bom contador de histórias poderia aprender de ouvi-lo, lido ou falado. [...] A performance e a recepção oral para a transmissão do Evangelho de Marcos não é, de todo, improvável; teria sido, de fato, o meio típico"23.

Quais evidências ela aponta no texto escrito marcano para justificar sua declaração? Primeiro, a composição agrega diversos elementos que vão se somando, ao invés de seguir uma orientação linear que leva de um começo a um fim como somos acostumados no modo moderno da escrita. Por isso os relatos, aparentemente desconexos e repetitivos, são interligados pelo desenvolvimento de certos temas. Segundo, o tom combativo do texto que supõe o enfrentamento entre Jesus e os espíritos impuros, os adversários fariseus e escribas, as doenças, a multidão, e até os discípulos, apontam para a atmosfera normal de um mundo em constante luta e confronto. Terceiro, o caráter cooperativo onde tanto quem conta o relato como quem o ouve estão totalmente envolvidos na sua execução. O processo de ouvir gera a cooperação, que gera a identificação, que gera a compreensão. Assim composto o texto escrito de Marcos não pode ser devidamente entendido à parte da assunção desse processo. Dewey conclui: "Nosso pleno reconhecimento da oralidade-auralidade de Marcos pode transformar nossas interpretações acerca dele" 24 .

\footnotetext{
21 HORSLEY, 2010, p. 110.

22 FARIA, Lair Amaro S. Tradições orais e performances comparadas nos evangelhos de Marcos e $Q$. 2009. Dissertação (Mestrado em História Comparada) - Universidade Federal do Rio de Janeiro, Rio de Janeiro, 2009. p. 133s.

23 DEWEY, 1994, p. 146.

${ }^{24}$ DEWEY, 1994, p. 156.
} 


\section{O relato oral e a análise da narrativa}

Metodologia de análise de textos literários associada ao advento da nova crítica literária, a narratologia ${ }^{25}$ foca exclusivamente o trabalho composicional do autor como um produtor de narrativas. Por meio dos métodos e recursos dispostos pela narratologia, uma composição literária é examinada quanto à organização do enredo narrativo, da disposição do tempo e do espaço, da apresentação dos personagens, da focalização e assim por diante.

No evangelho, Marcos seria o criador de uma narrativa da qual brota uma apresentação ou testemunho de Jesus de Nazaré. A obra marcana possui um plano narrativo sustentado pelo enredo, que é o seu elemento sequencial e dinâmico. Esse é composto por pequenas narrativas episódicas. Em geral, cada episódio possui um enredo próprio muito simples, normalmente em cinco pontos: alguém vai até Jesus ou é levado até ele; uma dificuldade é apontada; Jesus age de modo a sanar a dificuldade; superada a dificuldade, a pessoa recomeça a vida. Assim, cada episódio é uma narrativa testemunhal de Jesus de Nazaré. Quando somados um ao outro e a outro, sucessivamente, os episódios vão compondo uma narrativa testemunhal global sobre ele. ${ }^{26}$

$\mathrm{O}$ encadeamento de pequenas narrativas testemunhais umas às outras é feito por meio de encaixes, em que a pequena narrativa é habilmente integrada no enredo global formulado pelo narrador. $\mathrm{O}$ enredo global é moldado na sequência narrativa que vai do batismo até a ressurreição de Jesus. As narrativas testemunhais são colocadas entre o início da missão de Jesus até o seu fim na chegada a Jerusalém. Elas seguem o percurso geográfico do pequeno círculo de discípulos no reduto galilaico até sua expansão máxima nas regiões sírio-fenícia e transjordânica, com uma multidão de seguidores. Esse caminho percorrido por Jesus é pontilhado de pequenos episódios que aumentam o conhecimento sobre ele. Até que, ao final, seja conhecido plenamente como o Ungido Filho de Deus.

Concentrada no relato pessoal, a análise da narrativa não se ocupa da transmissão oral, apenas da narrativa individual de uma ou mais pessoas. Esse modo de aproximação do depoimento individual simplifica e permite a relação direta do ouvinte-leitor com os relatos individuais marcanos. Visto que todo relato individual é, necessariamente, uma narrativa de vida, a narratologia com seu interesse concentrado nos elementos narrativos do relato pode, perfeitamente, complementar o modo de análise propondo padrões e critérios para o exame do conteúdo do relato: a história e os muitos modos como ela é contada: a performance.

\section{Um exemplo}

Dessa forma, para um estudo dos relatos orais que compõem a tradição oral pré-marcana, temos que observar os traços de oralidade presentes: no texto escrito como sugere Kelber; no conjunto da tradição sinótica, procurando pelas divergências

\footnotetext{
${ }^{25}$ Narratologia é: "a teoria de narrativas, textos narrativos, imagens, espetáculos, eventos; artefatos culturais que 'contam uma história'. Tal teoria ajuda a entender, analisar e avaliar narrativas" (BAL, Mieke. Narratology. Introduction to the theory of narrative. 2. ed. Toronto: Toronto University Press 1997. p. 3).

${ }^{26}$ MARGUERAT, Daniel; BOURQUIN, Yvan. Para ler as Narrativas Bíblicas. Iniciação à Análise Narrativa. São Paulo: Loyola, 2009. p. 55, 56.
} 
entre os diversos textos como propõe Dunn; e na cadeia de transmissão oral como prescrevem Vansina e Bailey. Desde que muitos dos relatos orais são constituídos por narrativas, propomos que eles sejam analisados usando a metodologia da análise da narrativa (Narrative Analysis), considerando duas de suas contribuições: o plano ou enredo, e o foco ou perspectividade a partir do narrador e dos personagens.

Supondo que as teorias examinadas estão corretas e que o texto escrito do Evangelho de Marcos traz consigo as marcas da oralidade, a título de verificação, tomemos o exemplo da cura da mulher com hemorragias. Comecemos pelo relato oral conforme transcrito e editado nos três evangelhos de acordo com o modelo analítico de Dunn ${ }^{27}$ :

\begin{tabular}{|c|c|c|}
\hline Mateus 9.19-22 & Marcos 5.24-34 & Lucas $8.42 b-48$ \\
\hline $\begin{array}{l}\text { Levantando-se, } \underline{\text { Jesus o }} \\
\text { seguia com seus discípulos. } \\
\text { Ora, uma mulher que padecia } \\
\text { de hemorragias havia doze } \\
\underline{\text { anos aproximou-se por trás e }} \\
\text { tocou na franja da sua veste. } \\
\underline{\text { Ela dizia consigo: "Se eu }} \\
\underline{\text { conseguir somente tocar em }} \\
\underline{\text { sua veste, serei salva". Mas }} \\
\text { Jesus, voltando-se e vendo-a, } \\
\text { disse: "Confiança, minha } \\
\underline{\text { filha! A tua fé te salvou". E }} \\
\text { desde aquela hora, a mulher } \\
\text { ficou salva. }\end{array}$ & 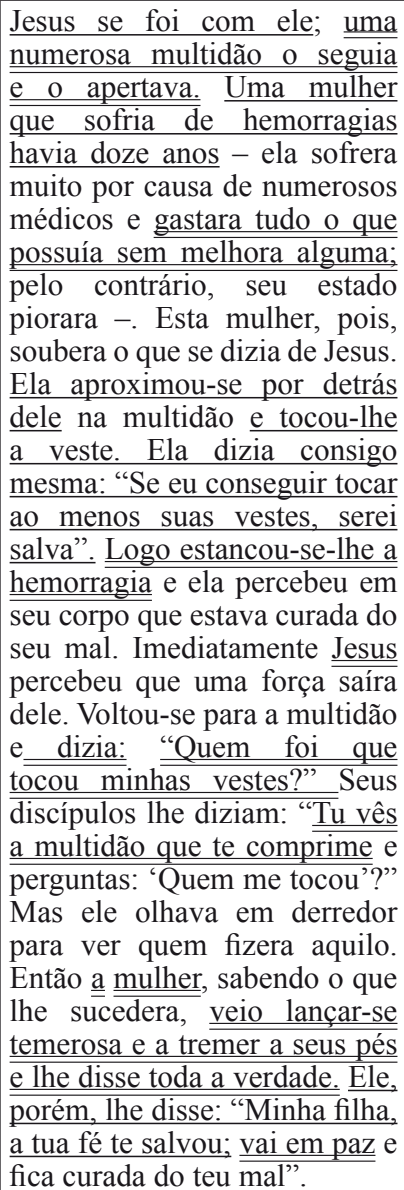 & 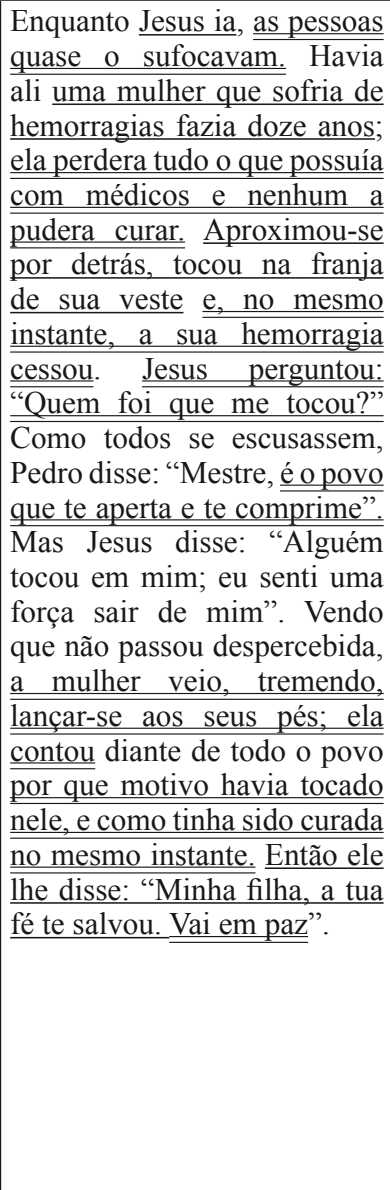 \\
\hline
\end{tabular}

* Aproximamos a correspondência comum aos três evangelhos, ou entre dois deles, com ( $\underline{x})$, e a correspondência comum a Marcos e Lucas com ( $\underline{x})$. Onde não há nenhuma marca, temos as divergências entre eles. (Os textos foram traduzidos por minha iniciativa.)

${ }^{27}$ DUNN, J. D. G. Jesus, Paulo e os Evangelhos. Rio de Janeiro: Vozes, 2017. p. 56. 
As três edições do acontecimento conservam a mesma ordem do enredo, sendo que Mateus, diversamente de Marcos e Lucas, retém o núcleo básico da narrativa. Marcos e Lucas tendem a expandir esse enredo, acrescentando comentários e informações adicionais, sendo mais abundantes em Marcos do que em Lucas. Enquanto Marcos opta pela dramaticidade do evento explorando a tensão entre a cura da mulher e a sua revelação a Jesus, Lucas é comedido, atribuindo a iniciativa somente a Jesus, acontecendo o mesmo em Mateus. Por outro lado, Marcos, com Mateus, explora o drama interior nos pensamentos da mulher. E ambos, com Lucas, a sensação de Jesus de ter saído uma força dele.

O relato de Marcos acentua o gosto popular pelos detalhes dos personagens, pela dramaticidade das suas ações, pela tensão que eleva o clímax até onde ele pode ser esticado. Os personagens são vivos, pensam e agem por si mesmos. A narrativa de Lucas tende a seguir Marcos, todavia optando pelo discurso direto e restringindo ao máximo o gosto do narrador por detalhes extravagantes do enredo. A narrativa mateana dá apenas um sumário dos acontecimentos, escolhendo o discurso indireto, exceto no momento em que Jesus dirige, sozinho, a fala à mulher.

Temos, destarte, três edições do mesmo acontecimento, nenhum deles sendo transcrição do original, porém versões diferentes oriundas de uma tradição oral baseada no testemunho de grande número de testemunhas. Todas revelam uma performance oral adaptada por um narrador a um auditório peculiar. Se assim foi, a transmissão dos testemunhos se deu de forma muito mais livre, informal, e sem os constrangimentos e as restrições de uma única testemunha, ou mesmo de uma congregação que determinasse o que seria válido e o que não seria contar acerca de uma cura de Jesus de Nazaré.

Sugerimos que as variantes narrativas entre os textos evangélicos do mesmo episódio de cura não se devem a atividades redacionais, coisa impensável do ponto de vista da cadeia de transmissão de tradição oral. Ao contrário, elas repercutem variações na cadeia de transmissão, onde diferentes performances sugerem que a narrativa de cura foi dita oralmente em um grande número de ocasiões acrescida de informações e detalhes que, posteriormente, foram incorporados à história que cada redator de evangelho teve à mão e redigiu no processo editorial evangélico.

Ora, de acordo com a tese de Dunn, onde os três evangelistas concordam entre si há uma tradição oral fixada na forma de um texto comum, conforme as denominadas teorias redacionais de escrita dos evangelhos. Inversamente, quando eles discrepam um dos outros, ou uns dos outros, temos a presença de relatos orais distintos aos quais tiveram acesso independentemente. Essas são marcas da oralidade. No texto sob exame, os três evangelistas, além de uma tradição escrita, obtiveram um ou mais testemunhos orais sobre a cura da mulher com hemorragias. Cada um deles recolheu desses as informações que julgou relevantes para a complementação do seu próprio relato, o que explica o fato das correspondências e discrepâncias em um único episódio. As correspondências, porém, de Marcos e Lucas mostram que ambos os evangelistas tiveram acesso a testemunhos próximos, onde prevaleceu maior (Marcos) ou menor (Lucas) variedade.

As similitudes entre os três evangelhos apontam que a marca da transmissão oral é a manutenção de um núcleo narrativo fixo, enquanto as formas vão se alterando, 
seja devido à progressão da transmissão oral, seja nas modificações das performances orais, seja no trabalho editorial. Seguindo o relato-base de Marcos, temos a seguinte formação oral regular subjacente ao texto escrito:
I. Exposição da doença
a) cenário do público (espectadores): numerosa multidão seguia e apertava a Jesus
b) chegada do curador e da doença: Jesus passava pelo caminho até Cafarnaum
c) indicação da doença: uma mulher que sofria com hemorragias contínuas
d) pedido de socorro: ela ouviu falar de Jesus, foi até ele e tocou suas vestes
e) desprezo ou ceticismo do público: o questionamento dos discípulos
II. Realização da cura
a) anúncio de uma fórmula de cura: não há indicação
b) gestos curadores: saiu uma força de Jesus
c) afirmação da cura: Jesus declara a cura

\section{Confirmação da cura}

a) fórmula de admiração/confirmação: Jesus confirma a cura

b) reenvio da pessoa curada: Jesus envia a mulher de volta para casa

c) injunção de guardar o segredo: não há indicação

d) propagação da reputação do curador: não há indicação

Outra marca da oralidade são as inserções linguísticas que remetem ao relato oral. No texto grego, mais do que nas traduções para a língua portuguesa, cada sentença é antecedida pela conjunção coordenada kai, 13 vezes, uma vez acompanhada do advérbio euthys. Ela é usada mais intensamente para a descrição da doença, para o momento da cura e, depois, para a revelação da mulher a Jesus e sua declaração de cura. A conjunção é menos frequente na discussão entre Jesus e os discípulos. Alinhando as diversas sentenças, o seu uso faz progredir a narrativa mantendo a sensação para o ouvinte-leitor de que tudo está acontecendo imediatamente como quando se relata um evento a alguém.

Os diálogos são introduzidos pelo uso do verbo legō: no imperfeito (elegen $=$ dizia), no presente (legeis $=$ dizes), no aoristo $($ eipen $=$ disse). Por meio deles passa-se da descrição e do discurso indireto para o discurso direto tornando presente o contato pessoal, assegurando a percepção de que eles estão acontecendo no momento do relato. Jesus e a mulher não somente falam um com o outro, também falam consigo mesmos em uma espécie de diálogo interior, mostrando os sentimentos que os movem internamente no exato momento dos acontecimentos.

A referência ao momento e ao modo da cura é repetida frequentemente, fixando o núcleo central da narrativa sobre o acontecido na mente de quem ouve. De fato, o evento é reencenado aos olhos do ouvinte: a mulher doente pensa em tocar nas vestes de Jesus, ela toca nas vestes de Jesus, Jesus sente que alguém tocou em suas vestes, os discípulos afirmam que todos tocam nas vestes de Jesus, Jesus insiste que alguém tocou em suas vestes, a mulher confessa a Jesus que tocou em suas vestes, Jesus autentica a cura da mulher que, na verdade, já aconteceu quando ela tocou nas 
vestes de Jesus. Todo o segredo da cura gira ao redor da força (dynamis) que saiu de Jesus e a fé da mulher quando ela tocou em suas vestes. O caráter performático é fruto do privilégio dado à ação dos personagens sustentada no diálogo dinâmico entre eles.

Muitas informações fornecidas no relato oral seriam de conhecimento único ou exclusivo dos personagens, ou de quem tivesse contato íntimo com eles e resultado de um depoimento, de um desvendamento da subjetividade de cada um em meio ao acontecimento, sugerindo uma pluralidade de testemunhos. $\mathrm{O}$ conhecimento das condições de saúde da mulher, os gastos com tratamento médico e seu empobrecimento por causa dele foram dadas por ela mesma ou por alguém que a conhecia bastante para dá-lo em seu lugar. O conhecimento que ela obteve da chegada de Jesus de Nazaré até o lugar onde vivia, e a notícia de que ele estava tão próximo foi-lhe dado por alguém anônimo, certamente algum ruído ou burburinho da vizinhança ou de alguém que chegou de longe junto com Jesus. Doravante, o conhecimento dos passos executados pela mulher: meter-se entre a multidão, ir por trás de Jesus, tocar na sua roupa é exclusivamente dela, senão de alguém que a acompanhava, o que parece excluído da narrativa, pois ela está sozinha e age sozinha. O conhecimento do que a mulher pensava enquanto se movimentava até Jesus faz parte de um monólogo interior, uma racionalização que pertencia somente a ela, sendo impossível a alguém penetrar seus pensamentos. O narrador dá vez ao pensamento da mulher no diálogo íntimo e particular ao invés de externá-lo em uma descrição ou declaração direta. O conhecimento da mulher que estava curada resultou da percepção de mudança física ocorrida em seu corpo, algo somente dela.

Assim, há várias perspectivas distintas sugerindo a participação e identificação com o relato oral. Após a introdução da situação, logo o narrador nos conduz pela perspectiva da mulher como se uma câmera colocada atrás dela nos levasse a ver e viver a sua ação, até seus pensamentos. Habilmente, ele apresenta a perspectiva de Jesus, que olha ao redor procurando quem tocou em suas vestes. E a dos discípulos, que também olham em redor e veem que qualquer pessoa poderia ter tocado nas vestes de Jesus. Esse jogo de perspectivas envolve o ouvinte de modo tal que ele é tomado por uma experiência real do acontecimento. Quando o narrador coloca esse relato em seu plano narrativo, o faz inserindo o testemunho da mulher na narrativa de Jairo, inclusive insinuando que o fato de Jesus ter parado para identificar a mulher teria motivado a morte da filha desse. Da perspectiva do narrador, porém, quando Jesus diz à mulher: "Filha, tua fé te curou" (5.34), é a mesma fé que é requerida de Jairo por Jesus mais adiante: "Não temas, mas apenas crê!" (5.35). Da sua perspectiva, a fé é a atitude humana que permite alcançar os benefícios propiciados pela ação de Jesus.

Todavia, o evangelho não se esgota na mera apresentação dos relatos. Ele não se limita a expor a doença e a cura. Ele os leva adiante para a confirmação da cura e a aclamação de Jesus de Nazaré como enviado de Deus para curar, sendo seus atos propagados em toda a parte. Isso demonstra que a intenção querigmática estava presente, desde o início, nas congregações cristãs retentoras da tradição oral como um testemunho, uma forma de dar divulgação a Jesus de Nazaré pela propagação de seus feitos e palavras, argumentando em favor da fé nele como o Ungido de Deus. A memória testemunhada dos acontecimentos não era um retorno ao passado, mas uma anuncia- 
ção do futuro, na verdade, uma antecipação dele na chegada do governo de Deus para cujos benefícios todos estavam convidados. $\mathrm{Na}$ forma mais clara do testemunho, ele apontava para Jesus de Nazaré e seus feitos que, por sua vez, apontavam para a vinda do Ungido esperado por todos.

\section{Considerações finais}

Em grande medida, os relatos orais transcritos para o Evangelho de Marcos procedem de uma ou mais tradições orais garantidas por uma cadeia de transmissão que os reteve como celebração da memória de Jesus de Nazaré. Conforme conclui Dunn:

Se Jesus fez coisas notáveis e controversas, a memória desses eventos sem dúvida também preencheu parte do espaço [o período entre Jesus e os evangelhos]. Essas memórias de Jesus estiveram em forma de tradição oral. Essas memórias foram compartilhadas, circularam, foram interpretadas, foram elaboradas, mas inicialmente quase inteiramente em formas orais ${ }^{28}$.

Os estudos recentes do Evangelho de Marcos concentraram-se no seu plano literário, especificamente abordando as várias estratégias narrativas e as consequências para a sua interpretação. Dewey declara que "os scholars do Novo Testamento estão começando a explorar as questões sobre como os meios oral/aural/textual da antiguidade influenciaram a composição e recepção de textos particulares" ${ }^{29}$. Kelber acrescenta que:

Nosso conceito da cultura escribal que produziu os textos evangélicos não deveria, portanto, ser confinado à textualidade, intertextualidade, fontes escritas, e dependências entre as fontes sem consideração das operações da memória que estão implícitas nas diversas reapropriações do passado feitas pelos evangelhos ${ }^{30}$.

Há falta de mais estudos concentrados na observação da evidência oral no texto escrito de Marcos. Sendo a sociedade ao redor dele predominantemente oral, contribui para seu conhecimento a abundância de estudos sobre os processos de oralidade nas antigas sociedades orais, sendo um deles proporcionado por Jan Vansina. Esses podem ser estendidos por meio de estudos comparativos para as sociedades orais e parcialmente orais que ainda subsistem no mundo moderno. Sem descuidar da afluência contemporânea da auralidade/oralidade e da inundação imagética nas mídias sociais das sociedades modernas totalmente letradas. ${ }^{31}$

${ }^{28}$ DUNN, 2017, p. 71.

${ }^{29}$ DEWEY, 1994, p. 148.

${ }^{30}$ KELBER, Werner. The case of the gospels: Memory's desire and the limits of historical criticism. Oral Tradition, v. 17, n. 1, p. 58, 2002. Disponível em: <http://journal.oraltradition.org/issues/17i/kelber>. Acesso em: 15 jan. 2019.

${ }^{31}$ KELBER, 2002, p. 55. 
Concluímos que examinar o Evangelho de Marcos a partir da oralidade traz diferenças na maneira como o apreciamos. Uma delas acontece quando alteramos nossa perspectiva de Marcos, passando de um texto escrito originalmente para um documento oral que reúne relatos e testemunhos orais em um ambiente cultural oral-aural. Outra diferença ocorre quando distinguimos no texto de Marcos, em comparação com Mateus e Lucas, diferentes e contrastantes tradições orais que podem ter convivido mutuamente entre as variadas congregações cristãs. Mais uma diferença temos quando percebemos que o estilo de Marcos construído sobre o que chamamos, hoje, de folclórico ou popular, nos distancia do aprendizado histórico-literário de centenas de anos para nos reinserir na dinâmica vivencial da comunicação oral-aural, nos forçando a rever conceitos e paradigmas tão cuidadosamente inculcados nas nossas mentes, exigindo uma reprogramação neural, como sugeriu James Dunn. Ainda mais uma diferença ocorre quando aceitamos Marcos como uma literatura popular destinada à execução para indivíduos não letrados, cuja ocupação e preocupação principal na vida eram sobre como se vestiriam, como comeriam, como beberiam no dia seguinte. Uma última diferença, não menos significativa, tem a ver com nosso conhecimento do Jesus histórico desde a construção testemunhal de Jesus de Nazaré e o apelo a ter fé individual nele perante as duras necessidades da vida e os dilemas colocados por elas sobre a existência humana individual, social e das nações.

\section{Referências}

BAILEY, Kenneth. Informal Controlled Oral Tradition and the Synoptic Gospels. Themelios, v. 20, n. 2, p. 4-11, 1995. Disponível em: $<$ https://pt.scribd.com/document/353281537/Article-Kenneth-Bailey-Oral-Tradition-Synoptic-Gospels>. Acesso em: 22 jul. 2018.

BAL, Mieke. Narratology. Introduction to the theory of narrative. 2. ed. Toronto: Toronto University Press, 1997.

DEWEY, Joanna. The Gospel of Mark as an Oral-Aural Event: Implications for Interpretation. In: MCKNIGT, Edgar V.; MALBON, Elizabeth S. (Eds.). The New Literary Criticism and the New Testament. Pennsylvania: Trinity, 1994. p. 145-163.

DUNN, James D. G. Jesus Remembered. Grand Rapids: Eerdmans, 2003.

. Jesus em Nova Perspectiva. O que os estudos sobre o Jesus histórico deixaram para trás. São Paulo: Paulus, 2013. . Jesus, Paulo e os Evangelhos. Rio de Janeiro: Vozes, 2017.

FARIA, Lair Amaro S. Tradições orais e performances comparadas nos evangelhos de Marcos $e$ Q. Dissertação (Mestrado em História Comparada) - Universidade Federal do Rio de Janeiro, Rio de Janeiro, 2009. p. 133s.

HORSLEY, Richard A. Oral and Written Aspects of the Emergence of the Gospel of Mark as Scripture. Oral Tradition, v. 25, n. 1, p. 93-114, 2010. Disponível em: $<$ http://journal.oraltradition. org/issues/25i/horsley>. Acesso em: 11 ago. 2017.

KELBER, Werner. Tradition Orale et Écriture. Paris: du Cerf, 1991. (Lectio Divina, 144). . The case of the gospels: Memory's desire and the limits of historical criticism. Oral Tradition, v. 17, n. 1, p. 55-86, 2002. Disponível em: < http://journal.oraltradition.org/issues/17i/ kelber>. Acesso em: 15 jan. 2019.

MARGUERAT, Daniel; BOURQUIN, Yvan. Para ler as Narrativas Bíblicas. Iniciação à Análise Narrativa. São Paulo: Loyola, 2009.

VANSINA, Jan. La Tradición Oral. Barcelona: Labor, 1966. 